\title{
KANDUNGAN FRAKSI SERAT SILASE LIMBAH PISANG (BATANG DAN BONGGOL) DENGAN KOMPOSISI SUBSTRAT DAN LEVEL MOLASES YANG BERBEDA SEBAGAI PAKAN ALTERNATIF TERNAK RUMINANSIA
}

\author{
A. MULYA, D. FEBRINA DAN T. ADELINA \\ Fakultas Pertanian dan Peternakan UIN SUSKA Riau \\ Jln. H. R Subrantas KM 15 Simpang Baru Panam-Pekanbaru \\ Email : moelya_andika@ymail.com
}

\begin{abstract}
Harvesting bananas will produce stems and stump that can be used as an alternative feed. One processing techniques to maintain the nutritional value is silage. This study aims to determine the content of the fiber fraction ie. Neutral Detergent Fiber (NDF), Acid Detergent Fiber (ADF), lignin, cellulose and hemicellulose from bananas waste silage with the composition of the substrate and the different levels of molasses. Research using a Completely Randomized Design factorial pattern with two replications. Factor A : the composition of the substrate, A1. stumps 100\% : stems 0\%; A2. 50\% stems : 50\% stumps; A3. 0\% stumps : 100\% stems. Factor B : the addition of molasses $0 \% ; 2.5 \%$ and $5 \%$. Data were analyzed using a completely randomized factorial design, the difference between treatments tested Duncan's Multiple Range Test (DMRT). The results showed banana waste silage with the composition of the substrate and molasses with different levels have moderate physical qualities and fiber fractions are NDF 57.86-89.63\%; ADF 34.44-46.20\%; lignin 11.75-17.19\%; cellulose $15.10-32.34 \%$; hemicellulose $11.66-55.18 \%$. Silage that contains $100 \%$ of banana stem with the addition of $5 \%$ molasses is the best result.
\end{abstract}

Keywords : by product, ensilage, $A D F, N D F$, lignin

\section{PENDAHULUAN}

Penyediaan pakan merupakan salah satu masalah yang sering dihadapi dalam usaha peternakan. Pakan berfungsi untuk memenuhi kebutuhan hidup pokok, pertumbuhan, reproduksi dan produksi, sehingga penyediaan pakan yang baik dalam jumlah yang cukup merupakan faktor utama keberhasilan usaha peternakan.

Ketersediaan pakan di daerah tropis sangat bergantung pada musim. Pada musim kemarau sering terjadi kekurangan pakan, kualitas yang rendah dan kontinuitasnya tidak stabil sebaliknya pada musim penghujan pakan melimpah. Salah satu cara mengatasinya adalah menggunakan bahan pakan alternatif. Murni et al. (2008) menyatakan bahan pakan alternatif dapat berasal dari limbah pertanian, hasil sampingan agroindustri, hasil ikutan ternak dan pengolahan ternak, limbah perikanan dan bahan pakan nonkonvensional.

Batang dan bonggol pisang merupakan salah satu limbah pertanian atau perkebunan yang dihasilkan dari pemanenan tanaman pisang. Ditinjau dari kandungan gizi serta ketersediaannya maka batang dan bonggol pisang dapat dimanfaatkan sebagai bahan pakan alternatif. Pengawetan bertujuan untuk mempertahankan nilai gizi bahan dan dapat mengatasi kekurangan pakan di musim kemarau. Salah satu teknik pengawetan adalah silase. Silase adalah metode pengawetan hijauan berdasarkan pada proses fermentasi asam laktat yang terjadi dalam kondisi anaerob.

Molases merupakan produk sampingan selama proses pemutihan gula pada industri gula tebu dan molases tidak dapat lagi dibentuk menjadi sukrosa namun masih mengandung gula dengan kadar tinggi $50-60 \%$, asam amino dan mineral (Mades et al., 2013). Kusmiati et al. (2007) menambahkan molases mengandung nutrisi cukup tinggi untuk kebutuhan bakteri, sehingga dapat dijadikan bahan alternatif sebagai sumber karbon dalam media fermentasi. Tingginya kandungan serat kasar pada batang pisang $(27,73 \%)$, NDF batang pisang $(78,84 \%)$ dan bonggol 
pisang $(64,151 \%)$ sehingga batang dan bonggol pisang susah dicerna oleh ternak, sehingga perlu diupayakan penurunan fraksi serat pada batang dan bonggol pisang terutama kandungan NDF, ADF dan lignin. Penelitian ini bertujuan untuk mengetahui pengaruh komposisi substrat dan level molases yang berbeda terhadap kandungan fraksi serat silase limbah batang pisang meliputi kandungan NDF, $\mathrm{ADF}$, hemiselulosa, selulosa dan lignin.

\section{MATERI DAN METODE}

\section{Bahan dan alat}

Pembuatan silase mengunakan batang dan bonggol pisang kepok dan molases. Untuk analisis fraksi serat digunakan $\mathrm{HCl}$, $\mathrm{K}_{3} \mathrm{SO}_{4}, \mathrm{MgSO}_{4}, \mathrm{NaOH}, \mathrm{H}_{3} \mathrm{BO}_{4}$, Eter, benzene, $\mathrm{CCl}_{4}$, aquades.

Peralatan yang digunakan adalah kantong plastik, timbangan, baskom, sendok pengaduk, cangkul, parang, mesin chooper, kamera, pemanas, gelas piala, spatula, pipet tetes, timbangan analitik Kjeltec, soxtec, fibertec yang dilengkapi dengan hot extraction dan cold extraction, kertas saring, tanur listrik, crucible, desikator dan alat destilasi, lengkap dengan erlenmeyer.

\section{Metode Penelitian}

Penelitian menggunakan Rancangan Acak Lengkap (RAL) pola faktorial $3 \times 2$ masing-masing dengan 2 ulangan.

Faktor A adalah komposisi substrat $\mathrm{A} 1=100 \%$ bonggol $+\quad 0 \%$ batang $\mathrm{A} 2=50 \%$ bonggol $+50 \%$ batang A3 $=0 \%$ bonggol $+100 \%$ batang

Faktor B adalah level molases

$\mathrm{B} 1=0 \%$

$\mathrm{B} 2=2,5 \%$

$\mathrm{B} 3=5 \%$

\section{HASIL DAN PEMBAHASAN}

\section{Kandungan NDF Silase Batang dan Bonggol Pisang}

Tabel 1 memperlihatkan kandungan Neutral Detergent Fiber (NDF) silase batang dan bonggol pisang.

Tabel 1. Rataan kandungan NDF silase batang dan bonggol pisang (\%)

\begin{tabular}{lrrrrl}
\hline \multirow{2}{*}{ Komposisi Substrat (A) } & \multicolumn{3}{c}{ Penambahan Molases (B) } & \multirow{2}{*}{ Rataan } \\
\cline { 2 - 4 } & B1(0\%) & B2(2,5\%) & B3(5\%) & \\
\hline A1 (Bo 100\% + Ba 0\%) & $88,74 \pm 5,04$ & $90,11 \pm 0,90$ & $90,05 \pm 3,60$ & $89,63 \mathrm{a} \pm 2,88$ \\
A2 (Bo 50\% + Ba 50\%) & $73,08 \pm 2,72$ & $75,95 \pm 2,57$ & $75,96 \pm 1,36$ & $75,00^{\mathrm{b}} \pm 2,32$ \\
A3 (Bo 0\% + Ba 100\%) & $57,58 \pm 2,87$ & $59,43 \pm 0,25$ & $56,54 \pm 1,22$ & $57,86^{\mathrm{a}} \pm 1,92$ \\
\hline Rataan & $73,13 \pm 14,21$ & $75,16 \pm 13,79$ & $74,18 \pm 15,16$ & \\
\hline
\end{tabular}

Ket : $\mathrm{Bo}=$ Bonggol, $\mathrm{Ba}=$ Batang.

Superskrip berbeda pada kolom yang sama menunjukkan pengaruh berbeda sangat nyata $(\mathrm{P}<0,01)$.

Kandungan NDF silase batang dan bonggol pisang berkisar 56,54-90,11\%. Komposisi substrat sangat nyata $(\mathrm{P}<0,01)$ menurunkan kandungan NDF silase. Penambahan molases tidak berpengaruh $(\mathrm{P}>0,05)$ terhadap kandungan NDF silase serta tidak ada interaksi antara penambahan molases dengan komposisi substrat silase.

Komposisi substrat silase mempengaruhi kandungan NDF dimana semakin banyak penambahan batang pisang maka kandungan NDF semakin menurun. Terjadi penurunan kandungan NDF seiring dengan penambahan batang pisang dalam substrat dimana perlakuan $\mathrm{A}$ (100\% bonggol : $0 \%$ batang) adalah $89,63 \%$, perlakuan B (50\% bonggol : 50\% batang) adalah $75,00 \%$ dan perlakuan C $(0 \%$ bonggol : 100\% batang) adalah 57,86\%. Menurunnya kandungan NDF silase seiring dengan penambahan batang pisang ini diduga terjadi perenggangan ikatan lignin dengan hemiselulosa oleh BAL yang menyebabkan hemiselulosa terlepas dari lignin. Hemiselulosa merupakan bagian 
dari NDF sehingga terlepasnya hemiselulosa dari lignin menyebabkan penurunan kandungan NDF. Sesuai pendapat Akmal (1994) menurunnya kandungan NDF selama fermentasi karena terjadi pemutusan ikatan ligno hemiselulosa dan lignoselulosa.

Kandungan NDF batang dan bonggol pisang sebelum silase adalah $78,84 \%$ dan $64,15 \%$ sedangkan kandungan NDF batang dan bonggol pisang setelah silase berkisar 57,86-89,63\%. Hasil NDF pada penelitian ini hampir sama dengan yang dilaporkan
Anas dan Andy (2010) silase 90\% jerami jagung $+10 \%$ daun gamal kandungan NDF yaitu 59,72\% tetapi lebih tinggi dari penelitian Karim (2014) silase 50\% jerami padi $+10 \%$ biomassa murbei $+40 \%$ konsentrat kandungan NDF adalah 54,81\%.

\section{Kandungan ADF Silase Batang dan Bonggol Pisang}

Kandungan Acid Detergent Fiber (ADF) silase batang dan bonggol pisang ditunjukkan pada Tabel 2.

Tabel 2. Rataan kandungan ADF silase batang dan bonggol pisang (\%)

\begin{tabular}{|c|c|c|c|c|}
\hline \multirow{2}{*}{ Komposisi Substrat (A) } & \multicolumn{3}{|c|}{ Penambahan Molases (B) } & \multirow{2}{*}{ Rataan } \\
\hline & $\mathrm{B} 1(0 \%)$ & $\mathrm{B} 2(2,5 \%)$ & $\mathrm{B} 3(5 \%)$ & \\
\hline $\mathrm{A} 1(\mathrm{Bo} 100 \%+\mathrm{Ba} \quad 0 \%)$ & $34,55 \pm 3,51$ & $32,11 \pm 0,05$ & $36,67 \pm 1,17$ & $34,44^{\mathrm{a}} \pm 2,63$ \\
\hline $\mathrm{A} 2$ (Bo $50 \%+\mathrm{Ba} 50 \%)$ & $35,81 \pm 1,03$ & $37,43 \pm 4,17$ & $36,27 \pm 0,80$ & $36,50 \mathrm{a} \pm 2,09$ \\
\hline A3 (Bo $0 \%+$ Ba 100\%) & $45,85 \pm 4,62$ & $45,12 \pm 0,69$ & $47,62 \pm 5,98$ & $46,20^{b} \pm 3,58$ \\
\hline Rataan & $38,74 \pm 6,14$ & $38,22 \pm 6,15$ & $40,19 \pm 6,38$ & \\
\hline
\end{tabular}

Ket : Bo = Bonggol, $\mathrm{Ba}=$ Batang.

Superskrip berbeda pada kolom yang sama menunjukkan pengaruh berbeda sangat nyata $(\mathrm{P}<0,01)$.

Tabel 2 memperlihatkan rataan kandungan ADF silase batang dan bonggol pisang berkisar 32,11-47,62\%. Komposisi substrat sangat nyata $(\mathrm{P}<0,01)$ mempengaruhi kandungan ADF silase. Penambahan molases tidak berpengaruh $(\mathrm{P}>0,05)$ terhadap kandungan ADF silase dan tidak ada interaksi antara komposisi substrat dengan penambahan molases terhadap kandungan ADF.

Terjadi penurunan kandungan ADF seiring dengan penambahan bonggol pisang diduga bonggol pisang memiliki kandungan ADF yang rendah, sesuai pendapat Anas dan Andy (2010) penurunan kandungan ADF disebabkan penambahan daun gamal yang mempunyai kandungan ADF lebih rendah dari jerami jagung dimana kandungan ADF jerami jagung lebih tinggi $(47,09 \%)$ dan daun gamal lebih rendah $(34,71 \%)$ sebelum dibuat silase.

Penurunan kandungan ADF juga diduga telah terjadi perenggangan ikatan selulosa dengan lignin sehingga selulosa meningkat dan terjadi penurunan ADF. Arief (2001) menyatakan menurunnya kandungan ADF disebabkan selama fermentasi terjadi perenggangan ikatan lignoselulosa dan ikatan ligno hemiselulosa yang menyebabkan isi sel yang terikat akan larut dalam neutral detergen. Kandungan ADF pada penelitian ini 32,11-47,62\%, nilai ini lebih rendah dibandingkan penelitian Anas dan Andy (2010) silase $70 \%$ jerami jagung $+30 \%$ daun gamal kandungan NDF adalah $42,11 \%$.

\section{Kandungan Hemiselulosa Silase Batang dan Bonggol Pisang}

Kandungan hemiselulosa silase batang dan bonggol pisang dapat dilihat pada Tabel 3 . 
Tabel 3. Rataan kandungan hemiselulosa silase batang dan bonggol pisang (\%)

\begin{tabular}{lrrrrl}
\hline \multirow{2}{*}{ Komposisi Substrat (A) } & \multicolumn{3}{c}{ Penambahan Molases } & \multirow{2}{*}{ Rataan } \\
\cline { 2 - 4 } & \multicolumn{1}{c}{ B1(0\%) } & \multicolumn{1}{c}{ B2(2,5\%) } & \multicolumn{1}{c}{ B3(5\%) } & \\
\hline A1 (Bo 100\% + Ba 0\%) & $54,19 \pm 8,54$ & $58,00 \pm 0,94$ & $53,37 \pm 1,17$ & $55,18 \mathrm{c} \pm 4,56$ \\
A2 (Bo 50\% + Ba 50\%) & $37,26 \pm 3,75$ & $38,52 \pm 1,60$ & $39,68 \pm 0,56$ & $38,49^{\mathrm{b}} \pm 2,13$ \\
A3 (Bo 0\% + Ba 100\%) & $11,72 \pm 7,49$ & $14,30 \pm 0,94$ & $8,96 \pm 4,82$ & $11,66^{\mathrm{a}} \pm 4,66$ \\
\hline Rataan & $34,39 \pm 19,85$ & $36,94 \pm 19,60$ & $34,01 \pm 20,48$ & \\
\hline
\end{tabular}

Ket : $\mathrm{Bo}=$ Bonggol, $\mathrm{Ba}=$ Batang.

Superskrip berbeda pada kolom yang sama menunjukkan pengaruh berbeda sangat nyata $(\mathrm{P}<0,01)$.

Komposisi substrat sangat nyata $(\mathrm{P}<0,01) \quad$ menurunkan kandungan hemiselulosa silase. Penambahan molases tidak berpengaruh $(\mathrm{P}>0,05)$ terhadap kandungan silase dan tidak ada interaksi antara komposisi substrat dengan penambahan molasses terhadap kandungan hemiselulosa silase.

Tidak adanya pengaruh molases dalam meningkatkan kandungan hemiselulosa diduga level molases yang ditambahkan belum mencukupi kebutuhan mikro organisme yang berperan dalam proses fermentasi serta tingginya $\mathrm{pH}$ yang didapat dalam penelitian ini berkisar 4,76-5,84. Selain itu semakin banyak batang pisang maka kandungan hemiselulosanya semakin menurun. Kandungan hemiselulosa tertinggi terdapat pada perlakuan $100 \%$ bonggol yaitu $55,18 \%$, dan kandungan hemiselulosa terendah yaitu 11,66\% dengan komposisi $100 \%$ batang.

Tingginya kandungan hemiselulosa pada perlakuan A1 (55,18\%) diduga bonggol pisang mengandung pati yang tinggi yaitu $67,79 \%$ yang dapat dimanfaatkan oleh mikroba sebagai sumber energi. Penurunan bonggol dalam substrat menyebabkan kandungan hemiselulosa juga ikut turun ini diduga pati pada batang pisang lebih sedikit $(59,24 \%)$ dibandingkan pada bonggol sehingga mikroba menggunakan hemiselulosa sebagai sumber energi selama proses fermentasi yang menyebabkan kandungan hemiselulosa pada A3 paling rendah yaitu $11,66 \%$. Sesuai pendapat McDonald (1991) hidrolisis hemiselulosa dapat dilakukan oleh mikroorganisme yang menggunakan gula sebagai substratnya sehingga terjadi pemecahan hemiselulosa selama tahap awal fermentasi dan bakteri asam laktat akan merombak hemiselulosa setelah karbohidrat habis terpakai dan membentuk asam organik.

Pratama (2014) menyatakan menurunnya kandungan hemiselulosa disebabkan telah terjadinya perenggangan ikatan lignohemiselulosa selama proses fermentasi, sehingga memudahkan penetrasi enzim hemiselulase untuk mencerna hemiselulosa menjadi sumber energi bagi mikroorganisme. Perez et al (2002) menyatakan hemiselulosa mengalami biodegradasi menjadi monomer gula dan asam asetat dengan bantuan enzim hemiselulase. Selanjutnyan Tilman et al. (1994) menyatakan hemiselulosa terdapat bersama-sama selulosa dalam struktur semua bagian tanaman tertentu, tidak dicerna oleh enzim-enzim yang dihasilkan jasad renik khususnya dalam rumen yang juga mencerna pati dan karbohidrat yang terlarut dalam air. Kandungan hemiselulosa yang didapat pada penelitian ini berkisar $8,96-58,00 \%$, nilai ini lebih tinggi dibandingkan yang dilaporkan Rahmawati (2014) pada silase rumput gajah $60 \%+0 \%$ konsentrat $+40 \%$ biomassa murbei kandungan hemiselulosa adalah $11,69 \%$.

\section{Kandungan Selulosa Silase Batang dan Bonggol Pisang}

Kandungan selulosa silase batang dan bonggol pisang terlihat pada Tabel 4 . 
Tabel 4. Rataan kandungan selulosa silase batang dan bonggol pisang (\%)

\begin{tabular}{|c|c|c|c|c|}
\hline \multirow{2}{*}{ Komposisi Substrat (A) } & \multicolumn{3}{|c|}{ Penambahan Molases (B) } & \multirow{2}{*}{ Rataan } \\
\hline & $\mathrm{B} 1(0 \%)$ & $\mathrm{B} 2(2,5 \%)$ & B3(5\%) & \\
\hline $\mathrm{A} 1(\mathrm{Bo} 100 \%+\mathrm{Ba} \quad 0 \%)$ & $16,82 \pm 0,22$ & $13,85 \pm 4,43$ & $14,64 \pm 2,03$ & $15,10^{a} \pm 2,58$ \\
\hline A2 (Bo $50 \%+$ Ba 50\%) & $35,81 \pm 1,55$ & $18,43 \pm 6,56$ & $19,48 \pm 2,75$ & $20,61^{b} \pm 4,17$ \\
\hline $0 \%+\mathrm{Ba} 100 \%)$ & $28,75 \pm 4,62$ & $31,85 \pm 0,69$ & $36,41 \pm 6,13$ & $32,34^{\mathrm{c}} \pm 4,76$ \\
\hline Rataan & $23,16 \pm 5,70$ & $21,38 \pm 9,09$ & $23,51 \pm 10,69$ & \\
\hline
\end{tabular}

Ket : Bo = Bonggol, $\mathrm{Ba}=$ Batang.

Superskrip berbeda pada kolom yang sama menunjukkan pengaruh berbeda sangat nyata $(\mathrm{P}<0,01)$.

Tabel 4 memperlihatkan komposisi substrat sangat nyata $(\mathrm{P}<0,01)$ meningkatkan kandungan selulosa silase. Penambahan molases tidak nyata $(P>0,05)$ mempengaruhi kandungan selulosa silase. Tidak ada interaksi antara komposisi substrat dengan penambahan molases terhadap kandungan selulosa silase.

Perlakuan A1 menghasilkan kandungan selulosa terendah yaitu 15,10\% nyata lebih rendah $(\mathrm{P}<0,05)$ dibandingkan perlakuan A2 dan A3, hal ini diduga terjadi perenggangan ikatan lignoselulosa yang menyebabkan mikroorganisme memanfaatkan selulosa sebagai sumber energi selama fermentasi sehingga menurunkan kandungan selulosa. Sesuai pendapat Widya (2005) enzim selulase merupakan salah satu enzim yang dihasilkan oleh mikroorganisme yang berfungsi untuk mendegradasi selulosa menjadi glukosa.
Penurunan persentase bonggol pisang dalam pembuatan silase meningkatkan kandungan selulosa, hal ini diduga kandungan selulosa bonggol sebelum silase yaitu 9,61\% lebih rendah dari batang yaitu 20,37\%, selain itu diduga bakteri asam laktat menggunakan karbohidrat terlarut sebagai sumber energi yang ada pada batang lebih tinggi dibandingkan bonggol sehingga selulosa yang dipakai sebagai sumber energi oleh mikroba hanya sedikit maka terjadi kenaikan kandungan selulosa silase. Kandungan selulosa pada penelitian adalah 13,85$36,41 \%$, lebih tinggi dibandingkan Rahmawati (2014) silase 60\% rumput gajah $+30 \%$ konsentrat $+10 \%$ biomassa murbei kandungan hemiselulosa adalah $10,68 \%$.

\section{Kandungan Lignin Silase Batang dan Bonggol Pisang}

Tabel 5 memperlihatkan kandungan lignin silase batang dan bonggol pisang.

Tabel 5. Kandungan lignin silase batang dan bonggol pisang (\%)

\begin{tabular}{|c|c|c|c|c|}
\hline \multirow{2}{*}{ Komposisi Substrat (A) } & \multicolumn{3}{|c|}{ Penambahan Molases (B) } & \multirow{2}{*}{ Rataan } \\
\hline & $\mathrm{B} 1(0 \%)$ & B2 $(2,5 \%)$ & $\mathrm{B} 3(5 \%)$ & \\
\hline $\mathrm{A} 1$ (Bo $100 \%+\mathrm{Ba} \quad 0 \%$ ) & $14,93 \mathrm{aA} \pm 2,44$ & $16,43 \mathrm{aAB} \pm 4,55$ & $20,20 \mathrm{aB} \pm 0,78$ & $17,19 \pm 3,37$ \\
\hline $\mathrm{A} 2(\mathrm{Bo} 50 \%+\mathrm{Ba} 50 \%)$ & 10,07 aA $\pm 0,64$ & $17,17 \mathrm{bB} \quad \pm 2,53$ & $15,02 \mathrm{abB} \pm 3,56$ & $14,09 \pm 3,81$ \\
\hline $0 \%+\mathrm{Ba} 100 \%)$ & $14,42^{\mathrm{aA}} \pm 0,55$ & 11,49 aA $\pm 1,11$ & $9,34^{\mathrm{aA}} \pm 0,13$ & $11,75 \pm 2,35$ \\
\hline Rataan & $13,14 \pm 2,66$ & $15,03 \pm 3,64$ & $14,85 \pm 5,12$ & \\
\hline
\end{tabular}

Ket : Bo = Bonggol, $\mathrm{Ba}=$ Batang.

Superskrip berbeda pada baris (huruf kecil) dan pada kolom (huruf besar) yang sama menunjukan pengaruh nyata $(\mathrm{P}<0,05)$.

Komposisi substrat dan penambahan molases tidak mempengaruhi kandungan lignin tetapi terdapat interaksi $(\mathrm{P}<0,05)$ antara komposisi substrat dengan penambahan molases terhadap kandungan lignin silase. Semakin banyak batang pisang dan molases yang ditambahkan (perlakuan A3B3) menghasilkan kandungan lignin terendah yaitu $9,34 \%$.

Rendahnya kandungan lignin pada perlakuan A3B3 diduga terjadi perombakan lignoselulosa oleh BAL sehingga selulosa terpisah dari lignin yang menyebabkan selulosa meningkat sedangkan lignin turun. Arief (2001) pada 
proses ensilase kandungan lignin akan mengalami perubahan karena terjadi perenggangan dan pemisahan lignoselulosa dan lignohemiselulosa, sehingga semakin tinggi kandungan selulosa akan menurunkan lignin. Ditambahkan Jamarun dan Nuraini (2000) perombakan dinding sel dan isi sel menyebabkan larutnya komponen kristal selulosa, lignin dan silika. Tillman et al, (1994) menyatakan lignin bersama-sama selulosa membentuk komponen yang disebut lignoselulosa, yang mempunyai koefisien cerna sangat kecil.

Pada penelitian ini juga terjadi penurunan kandungan lignin seiring dengan penambahan batang pisang, diduga perombakan dan degradasi lignin oleh bakteri menyebabkan penurunan kandungan lignin. Natasha (2012) menyatakan lignin merupakan senyawa polimer aromatik yang sulit didegradasi; degradasi lignin dapat membuka akses bagi enzim yang dihasilkan oleh bakteri dan kapang untuk perombakan selulosa dan hemiselulosa (Nelson dan Suparjo, 2011). Kandungan lignin pada penelitian ini berkisar 9,34-20,20\%. Nilai ini lebih rendah dibandingkan yang dilaporkan Mokoginta (2014) silase kulit nenas ditambah $20 \%$ molases kandungan lignin adalah $20 \%$.

\section{KESIMPULAN}

1. Komposisi substrat mempengaruhi kandungan fraksi serat silase batang dan bonggol pisang, tidak ada pengaruh penambahan molases terhadap kandungan fraksi serat silase batang dan bonggol pisang

2. Terdapat interaksi antara komposisi substrat dan molases terhadap kandungan lignin silase batang dan bonggol pisang yaitu semakin banyak batang pisang dan molases yang ditambahkan akan menghasilkan kandungan lignin terendah (9,34\%).

3. Komposisi $100 \%$ batang pisang dengan molases 5\% merupakan hasil terbaik karena menghasilkan kandungan lignin dan NDF terendah

\section{DAFTAR PUSTAKA}

Akmal. 1994. Pemanfaatan Wastelage Jerami Padi sebagai Bahan Pakan Sapi FH Jantan. Tesis. Pasca Sarjana Institut Pertanian Bogor. Bogor.

Anas, S. dan Andy. 2010. Kandungan NDF dan ADF Silase Campuran Jerami Jagung (Zea mays) dengan Penambahan Beberapa Level Daun Gamal. Agrisistem.6(2):77-81.

Arief, R. 2001. Pengaruh Penggunaan Jerami Padi Amoniasi terhadap Daya Cerna NDF, ADF dan ADS dalam Ransum Domba Ideal. Jurnal Agroland. 8:(2).208-215.

Jamarun, N. dan Nuraini. 2000. Kualitas berbagai jerami padi amoniasi. Prosiding Seminar Nasional Pengembangan Ternak Sapi dan Kerbau Fakultas Peternakan Universitas Andalas. Padang.

Karim, I. I. 2014. Kandungan ADF, NDF, Selulosa, Hemiselulosa dan Lignin Silase Pakan Komplit Berbahan Dasar Jerami Padi dan Beberapa level Biomassa Murbei (Morus alba). Skripsi. Fakultas Peternakan Universitas Hasanuddin. Makasar.

Kusmiati, R. Swasono, Tamat, J. Eddy dan I. Ria. 2007. Produksi Glukan dari dua Galur Agrobacterium sp. pada Media Mengandung Kombinasi Molases dan Urasil. Biodiversitas. 8(1):123-129.

Mades, F., Eldini dan Irdawati. 2013. Pengaruh Pemanfaatan Molase terhadap Jumlah Mikroba dan Ketebalan Nata pada Teh Kombucha. Prosiding Semirata FMIPA Lampung.

McDonald, P., A.R. Henderson and S.J.E. Heron. 1991. The Biochemistry of Silage. Chalcombe Publications 2nd ed. Centerbury.UK.

Mokoginta, I. 2014. Fraksi Serat Silase Kulit Nenas yang difermentasi dengan Penambahan Molases pada Level yang Berbeda. Skripsi. Fakultas Pertanian Peternakan UIN Suska Riau. Pekanbaru. 
Murni. R, Suparjo, Akmal dan B.L. Ginting. 2008. Buku Ajar Teknologi Pemanfaatan Limbah untuk Pakan. Laboratorium Makanan Ternak. Fakultas Peternakan. Universitas Jambi. Jambi.

Natasha, N. C. 2012. Variasi Komposisi dan Sumber Nutrisi bagi Miselium pada Proses Pelapukan Pelepah Kelapa Sawit untuk Mendegradasi Lignin dengan Pleurotus ostreatus. Skripsi. Fakultas Teknik Universitas Indonesia. Depok.

Nelson dan Suparjo. 2011. Penentuan lama fermentasi kulit buah kakao dengan Phanerochaete chrysosporium: Evaluasi kualitas nutrisi secara kimiawi. Agrinak. 1(1):1-10.

Perez,J., J. Munoz-Dorado., T. de la Rubia and J. Martinez. 2002. Biodegradation and biological treatments of cellulose, hemicelluloses and lignin: an overview. Int. Microbiol. 5:53-63.
Pratama, J. 2014. Kandungan ADF, NDF dan Hemiselulosa Pucuk Tebu (Saccharumofficinarum L) yang difermentasi dengan Kalsium Karbonat, Urea dan Molases. Skripsi. Fakultas Peternakan Universitas Hasanuddin. Makasar.

Rahmawati. 2014. Kandungan ADF, NDF, Selulosa, Hemiselulosa dan Lignin Silase Pakan Komplit Berbahan Dasar Rumput Gajah (Pennisetum purpureum) dan Beberapa level Biomassa Murbei (Morus alba). Skripsi. Fakultas Peternakan Universitas Hasanuddin. Makasar.

Tillman, A.D., H. Hartadi, S. Reksohadiprodjo, S. Prawirokusumo, dan L. Lebdosukojo. 1994. Ilmu Makanan Ternak Dasar. Gajah Mada University Press, Yogyakarta.

Widya. 2005. Enzim Selulase. http://kb.atmajaya.ac.id/default. aspx? tab $\mathrm{ID}=61 \& \mathrm{src}=\mathrm{a} \& \mathrm{id}=84059$ 